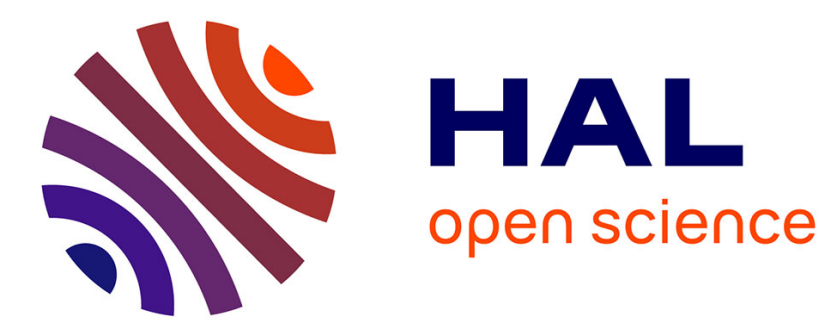

\title{
Evolution of Interface Structure in Ni-C Multilayers Depending on Annealing Temperature: Use of Embedded Co Sublayers-Markers
}

\author{
V. Chernov, N. Chkhalo, S. Nikitenko
}

\section{- To cite this version:}

V. Chernov, N. Chkhalo, S. Nikitenko. Evolution of Interface Structure in Ni-C Multilayers Depending on Annealing Temperature: Use of Embedded Co Sublayers-Markers. Journal de Physique IV Proceedings, 1997, 7 (C2), pp.C2-699-C2-700. 10.1051/jp4:1997209 . jpa-00255155

HAL Id: jpa-00255155

https://hal.science/jpa-00255155

Submitted on 1 Jan 1997

HAL is a multi-disciplinary open access archive for the deposit and dissemination of scientific research documents, whether they are published or not. The documents may come from teaching and research institutions in France or abroad, or from public or private research centers.
L'archive ouverte pluridisciplinaire HAL, est destinée au dépôt et à la diffusion de documents scientifiques de niveau recherche, publiés ou non, émanant des établissements d'enseignement et de recherche français ou étrangers, des laboratoires publics ou privés. 


\title{
Evolution of Interface Structure in Ni-C Multilayers Depending on Annealing Temperature: Use of Embedded Co Sublayers-Markers
}

\author{
V.A. Chernov, N.I. Chkhalo* and S.G. Nikitenko** \\ Siberian SR Center (SSRC) of Budker Institute of Nuclear Physics, Novosibirsk 630090, Russia \\ * Budker Institute of Nuclear Physics, Novosibirsk 630090, Russia \\ ** Institute of Catalysis, Lavrentiev 5, Novosibirsk 630090, Russia
}

\begin{abstract}
To verify the mechanism of epitaxial self-smoothing of interfaces in $\mathrm{Ni}(\mathrm{Co}) / \mathrm{C}$ multilayers annealed at optimum temperature, $\mathrm{Ni} / \mathrm{C}$ multilayers with embedded $\mathrm{Co}$ atoms-markers at a desired depth were studied. This depth-resolving EXAFS technique shows that mixed interfaces are separated at first stages of annealing followed by the crystallization of metal layers at the higher temperatures. The temperature of the interface separation coincides very closely with the temperature observed for a maximum multilayer reflectivity. These results are well explained by the decomposition of the metal glass-like region with carbon excess at the interface, simultaneously with coherent growth of metal (111) and graphite layers. Further bulk crystallization of the metal layers leads to the enhancement of interface roughness, and hence to a drastic decrease in reflectivity.
\end{abstract}

\section{INTRODUCTION}

EXAFS spectroscopy has proven to be a very informative technique in analysis of the local structure of $\mathrm{Ni} / \mathrm{C}$ and $\mathrm{Co} / \mathrm{C}$ multilayers [1-3]. In the previous work this method has allowed us to reveal the mixing of metal and carbon layers and also its effect on the structure of metallic layers depending on their thickness [2]. By combining EXAFS and XRD techniques to study strong structural changes in the $\mathrm{Ni}(\mathrm{Co}) / \mathrm{C}$ multilayers upon thermal annealing, we have been able to propose the mechanism of chemical separation with simultaneous epitaxial self-smoothing of the $\mathrm{Me} / \mathrm{C}$ mixed interface [3].

This paper presents in details this mechanism by means of EXAFS study of the local environment of the Co "markers" embedded into the Ni metal layers at a desired depth. The favorable possibility for this technique is based on almost identical chemical and physical properties of $\mathrm{Co}-\mathrm{C}$ and Ni-C systems. EXAFS measured in this way provides a depth-resolving tool enabling us to directly differentiate the interface and interior parts of a layer.

\section{EXPERIMENTAL}

The EXAFS measurements were performed at the EXAFS beamline of the VEPP-3 storage ring at the SSRC of the BINP, Novosibirsk. The electron beam energy was $2.0 \mathrm{GeV}$ and the maximum stored current was $100 \mathrm{~mA}$. The synchrotron radiation from a $2 \mathrm{~T}$ wiggler was monochromatized with a single-crystal $\mathrm{Si}$ (111) channel-cut monochromator. The Co $\mathrm{K}$ spectra were collected in the fluorescence mode using a Xe-filled gas electroluminescent detector for signal registration and a $(5 \% \mathrm{Ar}+\mathrm{He})$-filled ion chamber as Io monitor. The samples were measured in near-grazing geometry with the in-plane polarization of the incident beam. The $\mathrm{Ni}(\mathrm{Co}) / \mathrm{C}$ multilayers with $\mathrm{Co}(\mathrm{Ni})$ sublayers $(2 \AA)$ embedded into the $\mathrm{Ni}(\mathrm{Co})$ layers were prepared by a laser deposition technique. The parameters of the multilayers were chosen close to those used in practice: the Me layer thickness was $20 \AA$, carbon layer thickness $25 \AA$, the number of bilayers 60 . The multilayers were annealed sequentially $1.5 \mathrm{~h}$ in a high vacuum furnace. Because the data obtained for both systems were identical, we have focused on studying the $\mathrm{Ni} / \mathrm{C}$ multilayers with $\mathrm{Co}$ markers.

\section{RESULTS AND DISCUSSION}

Fig. 1 shows Fourier-transforms (FTs) of Co K-edge EXAFS data before and after thermal annealing for Ni/C multilayers with Co markers embedded at different depths. For better visualization of the mechanism under discussion, we select the samples with extreme structures: the Co sublayer at the bottom of the $\mathrm{Ni}$ layer (...-C-Co-Ni-C-..), the Co sublayer at the top of the $\mathrm{Ni}$ layer (...-C-Ni-Co-C-...) and the $\mathrm{Co}$ sublayer centrally positioned in the Ni layer (...-C-Ni-Co-Ni-C-...). The structural parameters of the first coordination shell were determined by EXCURV92 code [4] and are given in Table 1

Let us first consider the case of as-deposited samples. The FTs of the samples show two peaks in the nearest shell related to $\mathrm{Me}-\mathrm{C}$ and Me-Me bonds. This clearly demonstrates a high degree of intermixing of the layers. The short Me-C bondlength is due to their carbidic-like chemical nature. The absence of higher-shell structures indicates the amorphous-like atomic arrangement in metallic layers. These results show that the "metal" layers of the fresh-prepared multilayer consist of a metalglass core and diffuse interfaces oversaturated by carbon. 

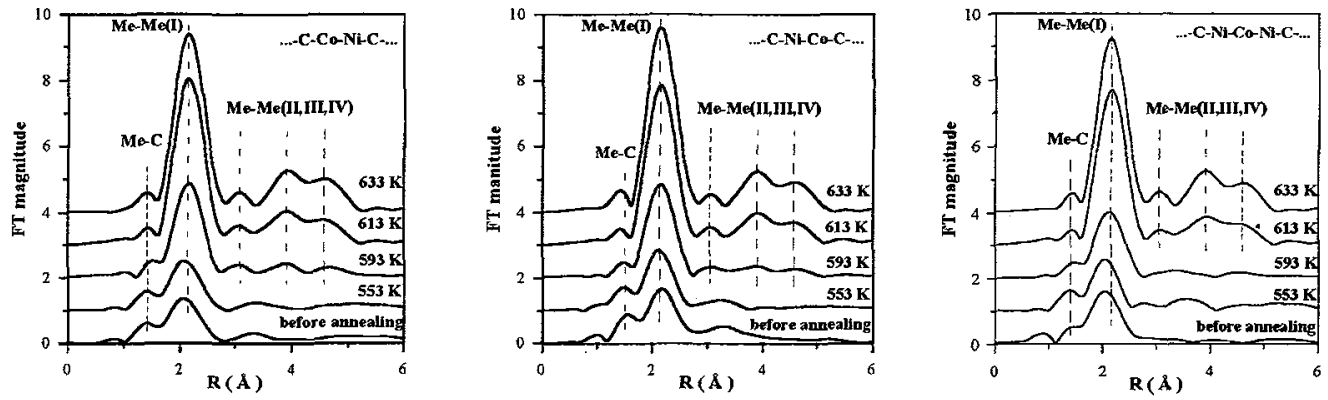

Figure 1: Fourier transforms of $\mathrm{k}^{3}$-weighted EXAFS of Co K-edge ( $\mathrm{k}$ range $\left.=3-11.5 \mathrm{~A}^{-1}\right)$ of the Ni/C multilayers with embedded Co markers before and under annealing. From left to right: ...-C-Co-Ni-C-...- Co atoms placed at the bottom of $\mathrm{Ni}$ layers; ...-C-Ni-Co-C-...- $\mathrm{Co}$ atoms at the top of $\mathrm{Ni}$ layers; ...-C-Ni-Co-Ni-C-...-Co atoms in the centre of $\mathrm{Ni}$ layers.

Starting with the annealing temperature $553 \mathrm{~K}$, little changes of EXAFS of the as-deposited and annealed samples can be seen. The best-fit results, reported in Table 1 , show that the Me-C coordination number decreases upon annealing while the Me-Me coordination mumber increases. These small changes are assumed to be due to relaxation processes characteristic to metallic glasses: the annealing-out of defects with changes in both topological and compositional short-range order.

The most interesting results were obtained in the vicinity of $590 \mathrm{~K}$ corresponding to a maximum of the multilayer reflectivity. A remarkable difference in the structures at the interface and center of the metal layer is clearly seen. While the core structure of the metal layer remains amorphous-like, the interface structure is rearranges as a crystalline-like type. The coordination numbers of the first Me-Me and Me-C shells at the interfaces increase and decrease respectively. Moreover, the second, third and fourth metal shells are clearly distinguished. Their intensity analysis by EXCURV92 code is fitted well with our model of the growing (111)-plane metal layer at the interface [5]. Hence the enhancement of the reflectivity at these temperatures can be explained by the formation of high-contrast and smooth interfaces.

Annealing at temperatures above $630 \mathrm{~K}$ leads to further bulk crystallization of the metal layer. EXAFS spectra of the layer look like one of polycrystalline foil. This rearrangement induces an enhanced roughness and therefore the reflectivity reduction.

Our results can be explained by a catalytic mechanism of decomposition of the Me-C solid solution (where Me is a dmetal) into graphite and bulk metal. In this case, the d-metal serves as a catalyst. This mechanism is directly connected with the coherent growth of the (111) metal planes and graphite layers [6]. From this viewpoint the $\mathrm{Ni}-\mathrm{C}$ and $\mathrm{Co}-\mathrm{C}$ systems are preferable to the other systems insofar as the mismatch of the lattice parameters is concerned. Annealing at moderate temperatures leads to multilayer stabilization by forming coherent planes with the surface $\mathrm{Me}-\mathrm{C}$ interaction. At higher temperatures the Me-Me bulk interaction plays a more important role than the energy of the Me-C interfacial interaction.

Table 1: Structural parameters determined by EXCURV92 for the first coordination shell.

\begin{tabular}{|c|c|c|c|c|c|c|c|c|c|c|}
\hline & \multicolumn{3}{|c|}{...-C-Co-Ni-C-... } & \multicolumn{3}{|c|}{$\ldots$...-Ni-Co-C-... } & \multicolumn{3}{|c|}{$\ldots-\mathrm{C}-\mathrm{Ni}-\mathrm{Co}-\mathrm{Ni}-\mathrm{C}-\ldots$} \\
\hline \multicolumn{2}{|c|}{ Annealing temperature } & $\mathrm{N}$ & $\mathrm{R} A$ & $2 \sigma^{2}$ & $\mathrm{~N}$ & $\mathrm{R}, \mathrm{A}$ & $2 \sigma^{2}$ & $\mathrm{~N}$ & $\mathrm{R}, \AA$ & $2 \sigma^{2}$ \\
\hline \multirow[t]{2}{*}{ after preparation } & $\mathrm{Me}-\mathrm{C}$ & 1.7 & 1.86 & 0.006 & 1.6 & 1.84 & 0.006 & 1.2 & 1.87 & 0.006 \\
\hline & $\mathrm{Me}-\mathrm{Me}$ & 4.0 & 2.41 & 0.020 & 4.4 & 2.43 & 0.019 & 4.6 & 2.42 & 0.021 \\
\hline \multirow[t]{2}{*}{$553 \mathrm{~K}$} & $\mathrm{Me}-\mathrm{C}$ & 1.3 & 1.85 & 0.006 & 0.9 & 1.85 & 0.006 & 1.1 & 1.86 & 0.006 \\
\hline & $\mathrm{Me}-\mathrm{Me}$ & 4.4 & 2.42 & 0.021 & 4.7 & 2.41 & 0.021 & 4.7 & 2.42 & 0.020 \\
\hline \multirow[t]{2}{*}{$593 \mathrm{~K}$} & $\mathrm{Me}-\mathrm{C}$ & 0.3 & 1.82 & 0.005 & 0.5 & 1.83 & 0.007 & 0.9 & 1.84 & 0.007 \\
\hline & $\mathrm{Me}-\mathrm{Me}$ & 6.2 & 2.44 & 0.022 & 6.4 & 2.43 & 0.021 & 4.9 & 2.42 & 0.019 \\
\hline $613 \mathrm{~K}$ & Me-Me & 10.5 & 2.44 & 0.020 & 10.3 & 2.43 & 0.020 & 9.8 & 2.42 & 0.018 \\
\hline $633 \mathrm{~K}$ & $\mathrm{Me}-\mathrm{Me}$ & 11.8 & 2.45 & 0.019 & 11.4 & 2.44 & 0.018 & 11.2 & 2.43 & 0.017 \\
\hline
\end{tabular}

\section{References}

[1] G.E. Dorssen, E.J. Puik, P.Mackle and H.A. Padmore, "Influence of annealing of Ni-C multilayer coatings using glancing angle fluorescence EXAFS", Sixth Int. Conf. on X-Ray Absorption Fine Structure (XAFS VI), York, Aug. 1990, S. Hasnain Eds. (Ellis Horwood, Chichester, 1991) p.245-247.

[2] V.A. Chernov, N.I. Chkhalo, M.V. Fedorchenko, E.P. Kruglyakov, S.V. Mytnichenko and S.G. Nikitenko, J. X-Ray Sci. Technol. 5 (1995) 65.

[2] V.A. Chernov, N.I. Chkhalo, M.V. Fedorchenko, E.P. Kruglyakov, S.V. Mytnichenko and S.G. Nikitenko, J. X-Ray Sci. Technol. 5 (1995) 389.

[4] N. Binsted, J.V. Campbell, S.J. Gurman and P.C. Stephenson, SERC Daresbury Laboratory EXCURV92 program (1991).

[5] V.A. Chernov and S.G. Nikitenko (to be published)

[6] R. Lamber, N. Jauger and G. Schulz-Ekloff, Surf. Sci. 197 (1988) 402. 